\title{
Migración y conflicto intercultural: del sol naciente a la tierra de Pachacamac
}

Recibido: $19 / 02 / 2020$

Aprobado: 20/05/2020

Vicente Otta Rivera

Publicado: $25 / 08 / 2020$

Universidad Nacional Mayor de San Marcos

<vottar@gmail.com>

\section{RESUMEN}

Explora y reflexiona sobre el mundo social de los migrantes japoneses en el Perú oligárquico. Analiza el contexto y la formación de la comunidad nissei a través de la historia de la vida singular de su padre y el proceso de construcción de una identidad cultural que marcó la historia y la memoria familiar actual.

Palabras clave: migración, interculturalidad, nikkei, conflicto, mestizaje cultural

\section{Migration and intercultural conflict: from the rising sun to the land of Pachacamac}

\author{
ABSTRACT \\ Explore and reflect on the social world of Japanese migrants in oligarchic Peru. Analyze the context and formation of the nissei \\ community through the history of his father's unique life and the process of construction of a cultural identity that marked the \\ history and current family memory.
}

KEYwORDs: migration, interculturality, nikkei, conflict, cultural miscegenation 
Todos los días son viaje y su casa misma es viaje. Entre los antiguos, muchos murieron en plena ruta... Matsuo Basho. La travesía de Yoichi.

\section{Población migrante y derechos}

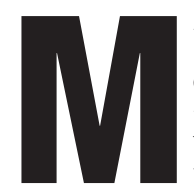

uy agradecido por la invitación para compartir esta mesa. Quiero felicitar a los organizadores de este evento, en particular a Humberto Rodríguez, porque el viene de una larga actividad académica, intelectual y, como ha mencionado, también de militancia política. Sus trabajos son de los pocos que han mantenido permanentemente el esfuerzo por visibilizar —en los últimos ańos se utiliza el termino visibilizar a la exposición pública de los que no tienen voz o no están visibles aun cuando juegan importantes roles en la sociedad-. La visibilización tiene mucho que ver con un término muy actual, la sociedad del espectáculo. Ahora, todo lo que no es parte del show no existe.

Humberto viene en de un periodo anterior, que tiene que ver con la reivindicación social, el reconocimiento de derechos, derechos que todas las personas y comunidades tienen de ser respetadas y valoradas en cualquier sociedad.

En el Perú, de los antropólogos vigentes, son pocos los que han trabajado de manera tan comprometida y sistemáticamente el aporte de negros, chinos y japoneses, como Humberto Rodríguez.

Resumiendo, podemos decir que se trata de revalorar el rol de los sectores subalternos en la construcción de la patria, en la construcción del Perú, porque finalmente la sociedad la construimos todos, el país lo construimos todos, desde diferentes formas y ángulos. Por eso con el tiempo y la experiencia, cada vez más he ido valorando y reconociendo el importante trabajo que ha hecho Tito Rodríguez en los últimos 40 ańos por reivindicar a los olvidados, los marginados.

Como ustedes saben, en los últimos 40 años ha variado la sensibilidad, ha variado la cultura, $y$ ha variado el sentido del derecho, ahora se habla de enfoque de género, de los derechos de las minorías, de los afro descendientes, de los pueblos indígenas, y todo eso se genera a partir de 1980, antes no recibía tanta atención.
¿Qué ha sucedido? Ha sucedido que a nivel global hay una expansión del sentido del derecho, una sociedad cada vez más sustentada en lo jurídico y en la igualdad, por lo menos legalmente.

En el Perú hay dos hechos que a nivel jurídico y político son muy importantes:

- La Constitución política del año 1979, que consagra las reformas fundamentales del gobierno de Velasco Alvarado (Reforma Agraria, Ley de Comunidades Nativas, Educación Intercultural, entre otros) que se constituyen en bases para la adquisición de ciudadanía de la población indígena y campesina, hasta entonces excluidas de los derechos ciudadanos.

- El Convenio OIT-169. El año 1989 la organización internacional del trabajo -OITque es un órgano de la Organización de las Naciones Unidas - ONU- genera el convenio 169 que, por primera vez en la historia jurídica universal, consagra el reconocimiento de los derechos indígenas. Todos los debates y conflictos a los que hemos asistido en los últimos 30 ańos, incluyendo los sucesos de Bagua en el año 2009 con Alan García, tienen como sustento jurídico el Convenio 169.

Hay una fuerte controversia sobre la Consulta Previa que define los derechos indígenas en la Amazonia y los Andes. Esta indica que cualquier modificación de su hábitat, su territorio, sea construir una carretera, explotación minera, gasífera, construcción de una escuela o posta médica, lo que sea, tiene que ser consultada con los pueblos indígenas, y si por a, b, c razones ellos no están de acuerdo, no procede. Por supuesto que en el $90 \%$ de los casos esta consulta no se realiza o su resultado es letra muerta, pero hay un sustento jurídico para estos reclamos.

Ecuador, es el ejemplo más claro y contundente del valor del empoderamiento indígena. La reciente movilización social en que los indígenas jugaron un rol protagónico, que ha terminado torciéndole el brazo al proyecto abiertamente neoliberal, antinacional de Lenin Moreno, en gran parte ha sido consecuencia de la movilización de los pueblos indígenas en defensa de sus derechos. En nuestro país los pueblos indígenas no tienen todavía esa potencia, esa fuerza, por razones que no es momento de explicar. Este es el primer aspecto jurídico. 
¿A dónde queremos ir? a dialogar sobre un proyecto de sociedad, un Estado que sea capaz de reconocer realmente estos derechos. Es en el fondo el sentido de este diálogo, es su sentido más importante.

¿Por qué me ha dado interés y curiosidad esta conversación? Lo ha dicho también Humberto acá; para ver cómo la presencia de nuestros ancestros sigue vigente y hasta qué punto se reproduce en nosotros, en las generaciones pos migrante.

Es en estos últimos años que he pensado más sobre este tema a propósito de la relación con mi padre, que no fue muy armoniosa. He empezado a entenderlo y a valorarlo mejor cuando me he ido haciendo mayor, y sobre todo cuando ya me estoy poniendo viejo, y les voy a explicar por qué. Tiene que ver con una historia de vida muy particular.

Lo que quiero decir ahora es que la presencia de los chinos y japoneses, como ahora los cientos de miles de migrantes venezolanos, es parte de la historia de la humanidad que siempre ha sido migrante, desde la teoría que dice que los primeros habitantes de América vienen del Asia, cruzando el estrecho de Bering, todos nos movemos y nos hemos movido siempre. El ser humano es un ser trashumante.

Pero hay hechos históricos y sociales, que son los que determinan los destinos individuales, esto es, que como personas, como individuos somos como una hoja seca al viento que no sabemos a dónde vamos ni por qué vamos, porque hay fuerzas y procesos que escapan totalmente de nuestro control que muchas veces determinan esta trashumancia. Es el caso de los japoneses y los chinos que llegaron a nuestro país en el siglo XIX.

En este proceso migrante existe una doble relación, el país que los recibe, Perú, y los países de los que salen, Japón y China.

\section{Por qué salen y por qué el Perú los recibe}

\section{a. Migración japonesa}

En el caso de Japón, haremos una comparación con la historia europea para entenderlo mejor.

Cuando cae el imperio romano, se produce la disgregación de todo el sistema imperial y se forman los poderes locales, el sistema feudal. Esto produce la recomposición de los feudos y reinos, y el debilitamiento de las monarquías.

En el caso de Japón hay también un sistema imperial que entra en crisis y se disuelve entrando al siglo XVII y, es reemplazado por lo que se llama el shougunato, que es un sistema donde el país se organiza alrededor de grandes señores feudales, los samuráis, los daimios, donde cada uno define su espacio de control territorial según el grado de fuerza militar que posea Se organizan y eligen a un señor feudal, al más fuerte, al más hábil, y lo convierten en el Shogun, que se transforma en el gobernante político militar del país.

El emperador ha dejado de ejercer el poder político y se dedica a actividades religiosas y artísticas, el sistema imperial deja de funcionar. Esto dura hasta la segunda mitad del siglo XIX, 1867-1868.

Entonces se organiza una coalición de fuerzas que repone al emperador. Este proceso se conoce como la era Meiji, el emperador que asume la reconcentración del poder es Meiji, y va a gobernar 44 años.

Esta era Meiji es la que reorganiza al Japón, lo reubica en el contexto mundial y lo convierte en una potencia. Produce cambios notables en los ámbitos económicos, sociales y militares. Reorganiza y fortalece el estado central. Este Japón de la era Meiji es el que va a durar hasta la actualidad. Es el que produce la industrialización y modernización de Japón, que convertido en gran potencia va a participar en la Segunda Guerra Mundial enfrentando a Estados Unidos. Esta es la importancia que tiene la era Meiji.

Como en toda reestructuración social a gran escala hay perdedores y ganadores; importantes clanes y seńores feudales que no quieren el retorno del sistema imperial, se oponen a la entronización de Meiji y son derrotados militarmente. Los que apoyan la subida al poder del emperador Meiji van a formar parte de la nueva corte imperial y tener las prebendas, ventajas y beneficios que eso supone. Los que caen en desgracia, son condenados a hacerse harakiri o a la pobreza, terminan fuera del nuevo poder.

Esta reorganización de la sociedad, que incluye un rápido proceso de industrialización y urbanización, va a producir una masa de gente excedente, que es la que tiene que emigrar.

Hay otro factor que requiere mayor información, una lectura más fina, que es necesario a tener 
en cuenta en la migración japonesa, es la presencia de los okinawenses.

Cuando se centraliza y reorganiza el estado japonés y se convierte en potencia comienza a desarrollar una vocación imperial y guerrera. Una de las primeras consecuencias es la anexión de Okinawa a Japón —año 1879—, Okinawa era un reino independiente hasta este momento.

Cuando el Estado japonés se fortalece los derrota militarmente y los anexa. Como toda dominación produce situaciones injustas y desventajas en el que es dominado. Por tal razón, la mayor parte de los migrantes japoneses, estimo que un 70\%, de los migrantes de origen japonés en el Perú es de procedencia okinawense que se identifican como ochinanchus, que recién se han empezado a visibilizar en los últimos 20 años, reivindican y reafirman sus diferencias con el Japón.

Dicen, no somos japoneses, nosotros somos okinawenses.

\section{b. La migración China}

Hacia 1840, las potencias europeas, Inglaterra, Francia y Alemania estaban instaladas en territorio chino y se disputaban áreas de influencia para expresar su poder colonial. Japón, convertido en potencia a partir de 1880 también inicia su expansión a costa de China y produce la primera invasión a la Manchuria los años 1894-1895.

Voy a realizar una somera explicación sobre el contexto de la migración China porque después vienen los descendientes chinos y ellos explicaran mejor su origen. Solamente voy a dar un par de ideas que son importantes para entender este proceso.

Hasta inicios del siglo XIX China tenía el mismo nivel de desarrollo económico y de acumulación, que Europa Occidental. Por eso la emergencia de China de 1950 al 2000 y convertirse ahora en una potencia de primer nivel sorprende porque no se conoce la historia de China en su larga duración. China está en un proceso rápido de desplazar a Estados Unidos de la hegemonía mundial.

Hasta 1800, China tenía un PBI igual que Inglaterra o Francia; lo que quiero decir es que la emergencia, su reencuentro con el camino del desarrollo no es producto de Deng Xiao ping o los últimos 30 años, no, es retomar una ruta de desa- rrollo civilizatorio potente que ha mantenido China durante los últimos 2000 ańos, y que tiene un interregno entre 1840 - 1940, hasta el triunfo de la revolución democrática popular que dirige Mao Tse Tung. Cuando los comunistas chinos toman el poder, reconstruyen China y la catapulta a la modernidad y liderazgo mundial.

Durante ese periodo, 1849 que viene la primera migración China, lo que ha ocurrido ha sido el estancamiento, una crisis del Sistema imperial, la anarquía social que facilita la invasión de varios países europeos para repartirse China, pero como China es tan grande, entonces son como piojos queriendo comerse un elefante. En el caso de Japón era algo absurdo, jamás iba a poder dominar China. Los únicos extranjeros que lograron dominar China fueron los mongoles en el siglo XII, pero los mongoles tenían una gran población y también un gran ejército.

Es en este contexto histórico, de invasión europea, que se produce la migración de los culíes.

¿Por qué son recibidos en Perú? Porque el Perú necesitaba mano de obra. Trajeron a los esclavos de origen africano, luego vienen culíes chinos en el año 1849, posteriormente, mano de obra japonesa en el año 1999. Por una razón muy sencilla, el Perú no había recuperado la severa depresión demográfica sufrida durante la colonia.

Los estudios más serios dicen que cuando llegan los espańoles y se inicia el periodo de la conquista, en el Perú había entre 10 y 12 millones de antiguos peruanos. Cuando comienza el siglo XVII, o sea 1600, eran millón y medio, se ha producido una catástrofe demográfica brutal, han muerto 9 de cada 10, si ustedes se dan cuenta, eso es algo difícil de imaginar. Son cosas que ahora no escandalizan, que parecen normales, por la visión europeizante del proceso de construcción del país, que hasta la actualidad sigue considerando a los indios como sujetos de segunda o tercera categoría. Menos humanos que el resto. El año 2009, un presidente se atrevía a decir que los indígenas eran ciudadanos de segunda categoría. ¡En pleno siglo XXI!

La terrible depresión demográfica creó un problema de déficit de mano de obra, de aguda demanda de fuerza trabajo.

La terrible depresión demográfica es lo que obliga a los propietarios de las haciendas cañeras y minas, mayoritariamente hijos de los colonialistas, enco- 
menderos, que al no tener indios que les trabajen la tierra y minas tienen que traer, primero negros, como esclavos y cuando eso ya es muy complicado traen chinos, y como sigue faltando mano de obra, vienen japoneses, esa es la razón principal de la presencia de población africana, china y japonesa migrante en nuestro país.

Ahora que estamos a portas de celebrar los 200 años de independencia, sería oportuno preguntarse ¿de qué independencia se habla? porque lo que no hizo esta independencia, fue incorporar a los indios al proceso independentista ni al nuevo Estado que surge en 1821. En ese momento había más de dos millones de habitantes y de esa población, el 80\% era indio, y ese indígena no tiene ninguna participación en el nuevo Estado republicano que se crea en 1821. Esto quiere decir que no se forma un Estado nacional, es un estado criollo-oligárquico, de los hijos de los españoles, esencialmente es un estado colonial.

En 1876 que se hace el primer censo en el Perú, con poca información veraz, dice que los peruanos eran entonces 2'600,000, había ya una cierta recuperación demográfica.

Los incas tenían censos casi todos los años, el sistema de quipus era un control de la riqueza que se producía y también poblacional.

Cuando vienen los japoneses en 1899 , se ha producido otro hecho histórico trascendental en el Perú

Se ha producido la derrota de la guerra con Chile, y esta derrota produjo entre otras cosas, una desorganización de todo el aparato económico. Los chilenos tenían una visión de estado, de perspectiva estratégica, y ellos sabían que toda guerra, implica un costo, que si no quieres pagarlo a futuro, tienes que destruir toda la capacidad económica del adversario, porque al final, la guerra no es sino la expresión militar de capacidades económicas y tecnológicas de los contendientes, toda guerra es eso, razón por la cual los chilenos destruyen toda la infraestructura de la costa peruana.

\section{Yoichi se afinca en el valle de Casma, Ancash}

Mi familia es oriunda del valle de Casma, provincia de la costa central a $360 \mathrm{~km}$ al norte de Lima. En la hacienda San Rafael, donde mi padre tenía su parcela agrícola, había existido un trapiche. Antiguamente había sido una hacienda de cultivo de caña de azúcar, había tenido su fábrica de azúcar pero casi nadie lo sabía. En la casa hacienda donde se concentraba la administración cuando era de un terrateniente, antes de la reforma agraria, había restos de maquinaria, entonces un día le pregunto a unos señores mayores, ¿por qué hay esos tubos, esos fierros? porque acá funcionaba un trapiche, aquí se producía azúcar, se hacía melaza, me responden. Entonces ¡cómo se destruyó esto, por qué ya no funciona? replico yo...durante la guerra con Chile, los soldados chilenos destruyeron todo, pasaban por todos los lugares y arrasaban, me respondieron.

La guerra con Chile fue otro factor de desestructuración que influyó en este requerimiento de mano de obra para reorganizar la producción de los valles costeros.

No olvidar además, que miles de negros libertos y chinos culíes se enrolaban en la tropa invasora pues los grandes hacendados y oligarcas los trataban de modo inhumano y preferían sumarse al invasor como búsqueda de libertad.

Dicho esto, quiero pasar a la parte biográfica propiamente; cómo influye la ascendencia en nuestra formación y en nuestro quehacer. Ya les dije en algún momento que he empezado a entender y a reconciliarme con mi padre ya maduro, y ahora que ya estoy medio viejo, lo entiendo mejor, y me relaciono mejor con él.

Cuando yo nací mi padre era ya un hombre viejo, esto es un serio problema, nací cuando él tenía 70 años, entonces imagínense, a los 70 años él ya era un hombre anciano. Llegaba a la casa a las 6 de la tarde a descansar, entonces viene su hijo de 7-8 ańos, a pedirle ir a jugar pelota, a volar cometa, mi padre no estaba en condiciones de hacer eso, un niño toma esta negación como expresión de desamor, de falta de atención, que no es capaz de compartir contigo, etc. Entonces tuve una mala relación, una relación muy conflictiva con mi padre, que recién después con el tiempo logré superar y, pude apreciar sus virtudes, sus cosas positivas.

Realmente es extraño, porque normalmente ese reconocimiento se produce en la nińez, etapa de la vida en que uno ve en el padre al superman, la figura mayor, y se establece una relación de imitación de ese modelo. De niño no viví ese proceso, al contrario, en toda esta etapa infantil y adolescente tuve complica- 
ciones con mi padre, nos peleábamos constantemente, más por mi rechazo que por el de él, y después cuando he empezado a verlo a la distancia, me doy cuenta que era un personaje, o sea, un tipo fuera de serie.

Recién ahora ya medio viejo he comenzado a reconstruir la idea del niño, mi admiración hacia él ha ido creciendo con los años.

Como buen oriental era parco, no le gustaba hablar mucho de su vida, aun cuando había sido muy peculiar.

No llega al Perú como trabajador, había sido marino, combate en la guerra ruso-japonesa en 19041905 y después viaja como marino mercante por casi todo el mundo y, en el año 1907, pasa por Perú y se queda accidentalmente. Cuando estaba de buen humor contaba cómo es que se queda. Al típico estilo marinero, los tripulantes del barco se quedan a tomar unos tragos y divertirse en el puerto del Callao, están ahí con las chicas de los bares, se queda dormido y el barco partió. Y lo dejan.

Me pareció una historia fantástica, cosa de película. Porque casi todos los japoneses han venido con contrato de trabajo, su caso era poco común. Tengo una gran estimación y valoración de su palabra (después les voy a contar eso de la palabra), pero en este caso siempre me quedó la duda, así que por formación y deformación de científico social me dije, hay que verificarlo, no es que desconfié de su palabra, pero vamos a verificarlo.

Hace unos años fui al Centro Cultural PeruanoJaponés, porque ahí está la relación de todos los migrantes, y les digo, en relación a mi padre, quiero saber qué año vino fulano de tal, cómo llegó, etcétera?

Ahí tienen dos relaciones, una donde están todos los que vinieron a través de contrato de trabajo y la otra de los que han venido por otros motivos; buscaron en la relación de contrato de trabajo y me dijeron acá no está; me preguntan, de dónde es su padre? él era de Ehime. Entonces me dicen, si es de Ehime tiene que está registrado en la asociación de la prefectura de Ehime, así que averigüe ahí y me dijeron sí, me dicen, su papá llega en 1907, lo que significa que forma parte de la primera ola migratoria, viene en un barco que se llama "Kasatu Maru" que quiere decir "La puerta de bambú". Viene en esa época y efectivamente había llegado así.
¿Por qué les comento esto? y acá viene la parte decisiva de su trayectoria de vida, porque cuando llega al Callao, su primera actividad laboral es el comercio, el negocio; se convierte en comprador de ganado, proveedor del camal de Lima. Salía a la periferia rural de Lima, compra ganado y provee al camal, pero unos 7, 8 ańos después termina afincado en Huaral, se va a Huaral porque ahí había japoneses establecidos; arrienda una chacra, se dedica a la agricultura y luego pone un restaurante.

\section{Huaral, un suceso peliagudo}

Le había comentado a Humberto, porque he leído su libro sobre Nikumatsu Okada, emigrante establecido en el valle de Huaral-Chancay en la década del 2010. Personaje importante de la comunidad japonesa, que en la década de 1920 se convierte en el mayor potentado japonés que hay en el Perú en ese momento. Es el primero en acumular una gran fortuna y se incorpora al grupo de poder del presidente Leguía, porque ustedes saben Leguía viene del norte, viene del negocio agrícola, él era hacendado y administrador de la hacienda Batán Grande, de Lambayeque y estaba relacionado con hacendados y agricultores,

Yo había escuchado una historia de mi padre sobre Nikumatsu Okada, ocurrida hace 90 años, esto es mucho antes que Humberto Rodríguez pensara escribir su libro sobre este personaje. Mi padre comentaba esta historia que tiene que ver con la cultura, la ética y el carácter. Es una historia complicada porque estando en Huaral, Okada le arrienda un terreno agrícola y siembra 15 hectáreas de algodón. Ustedes saben que en esa época había muy pocos notarios y contratos formales. Para empezar, no habían notarios o había muy pocos y, en segundo lugar, en esa época la gente valoraba mucho el compromiso verbal, lo que se llama la palabra. Hombre de palabra, es decir, si eres capaz o no de honrar tu compromiso. En esos términos arreglan con Okada, y cuando viene el tiempo de cosecha de algodón, Okada contrata personal y quiere cosechar, entonces mi padre le dice qué pasa acá yo he sembrado esta plantación, y Okada le responde, yo no te he arrendado. Así, terminan en el terreno judicial. Mi padre busca un abogado, pero Okada que tenía 


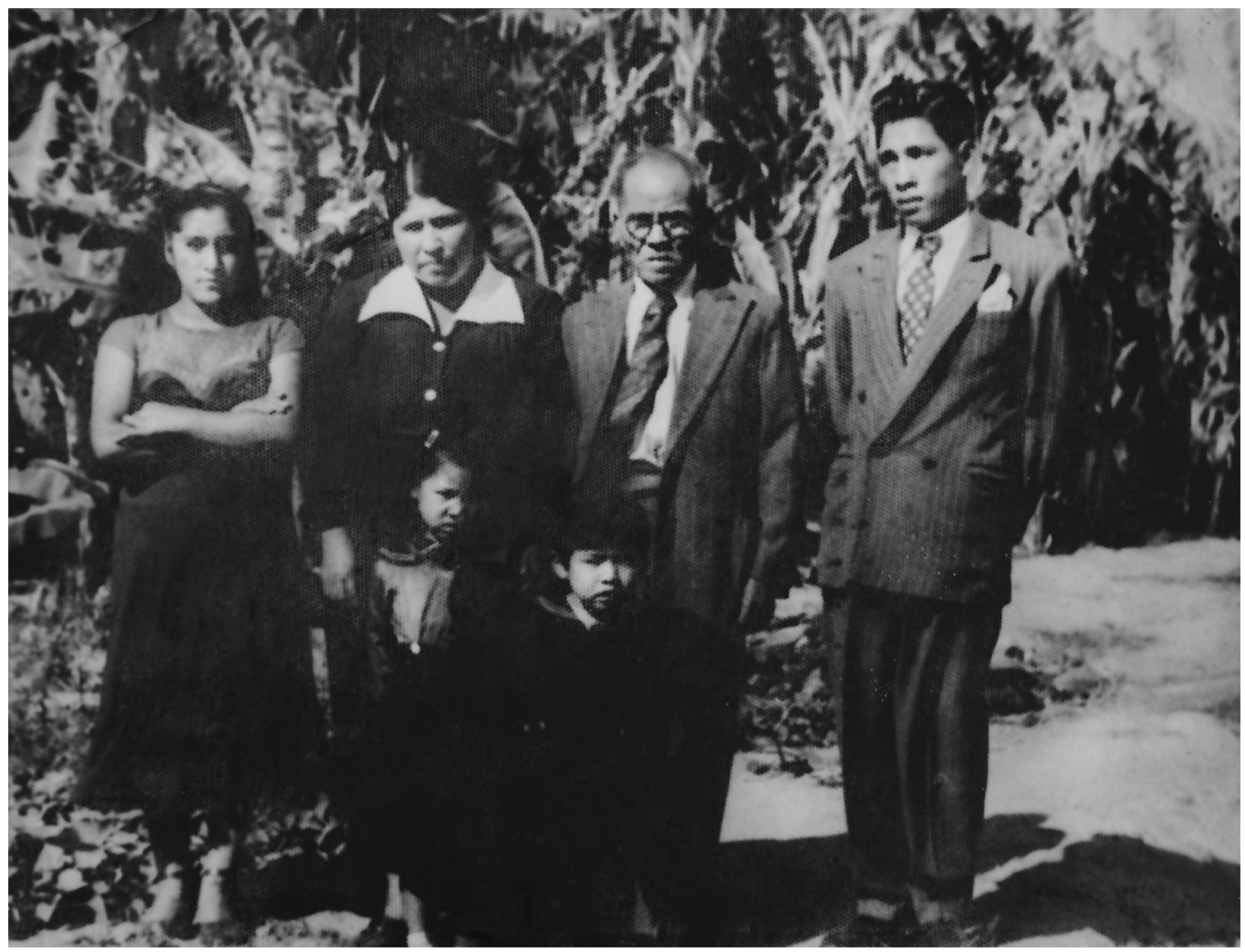

La familia Otta Rivera: padres, una prima y un hermano mayor, su hermana y Vicente, de 7 y 6 años, en la campiña de la ex-hacienda San Rafael, Casma-Ancash, 1956.

mucha plata y también influencia política y judicial gana en la primera instancia porque compra al abogado de mi padre. Ustedes se imaginan la reacción de mi padre que era un hombre del siglo XIX, era un hombre formado con influencia de la cultura samurái, les dice a sus amigos más cercanos que él tenía que matar a este estafador, no podía permitir tamaña estafa. Los amigos tratan de persuadirlo y le consiguen otro abogado, le dicen, todavía hay abogados honestos y le consiguen un abogado joven, que estaba empezando a litigar.

Este encara el juicio y lo saca adelante, y mi padre que era un hombre de hablar poco pero con toda franqueza le dice al abogado, sabe qué le dijo, yo tenía un abogado que me ha vendido el juicio, le explica todo lo sucedido; el abogado le dice no te preocupes, yo voy a ganar el juicio. Efectivamente lleva adelante el juicio y en un momento su adver- sario lo quiere sobornar, entonces él cita a mi padre y le dice ven a mi oficina a tal hora, quiero que estés ahí en esa conversación, cuando llega lo hace pasar a otro ambiente y Okada acude posteriormente y le ofrece dinero al abogado para que pierda el juicio, y este abogado lo rechaza y le dice que está actuando mal. Mi padre estaba escuchando en la habitación vecina. Esta historia se la he escuchado en el año 1960 cuando yo tenía unos 10 años, entonces no sabía quién era este señor Okada ni el abogado, años después ya he leído la biografía apologética que le ha hecho Humberto. Ya entonces conocía la otra versión.

También me enteré mucho tiempo después quien era este abogado. Ustedes son jóvenes, la mayoría no tiene idea de quién era este personaje, el abogado, pero es un señor que se llamaba Luciano Castillo, que fue un abogado de larga y brillante trayectoria, 
un tipo caracterizado por un gran sentido ético y profesional. 40 años después que mi padre contara esta historia me entero que el abogado era Luciano Castillo y comprendí que todo era verdad. Luciano Castillo, se convierte en unos años en figura política y referente socialista del norte peruano. Era una persona de gran integridad ética, incorruptible, es el que lleva el juicio y gana.

Lo que les quiero decir es lo siguiente, en el ámbito de los códigos éticos ese era el estilo de los contratos, de los compromisos. Tenían un gran sentido de responsabilidad, el valor sagrado de la palabra.

En el ámbito laboral no hay mucho que agregar sobre lo industrioso que son los japoneses, gente muy laboriosa y esforzada.

Otra cualidad que siempre me llamó la atención era su estilo de vida, era un tipo en verdad austero, He conocido pocas personas tan austeras y frugales como él, en general el japonés antiguo era así, muy frugal y austero, en su caso lo explico también por la experiencia de soldado combatiente.

No solamente provenía de un país que no es abundante en recursos naturales, donde no sobran las cosas de alimentación, sino también haber vivido una guerra; la guerra te condiciona muchas cosas, de sufrimiento, de dureza, que te marcan para toda tu vida.

No conozco a gente que haya sido tan frugal, en todas las cosas de la vida, en comer, en disfrutar y cosas por el estilo; él tenía tres comidas de lo más sencillas y saludables. Nunca le vi tomar agua sin hervir, nunca le he visto tomar agua gaseosa, toda la vida era agua caliente o té aunque sea frío pero té, agua hervida, que es lo que había siempre en la casa y muy poca carne, era casi vegetariano.

\section{El impacto de la guerra EE. UU.-Japón en la comunidad japonesa peruana}

Cómo se desarrolló la comunidad japonesa en el ámbito en el que yo nací. Es una experiencia traumática que ahora casi se ha olvidado.

Después de radicar varios años en Huaral Yoichi se va al valle de San Rafael en Casma, eso debe de haber sido más o menos 1930, en Casma había una comunidad japonesa bastante numerosa, unas $70 \mathrm{fa}-$ milias, y en Casma, la hacienda más grande y pro- ductiva del valle, era la ex-hacienda San Rafael, que tenía unas 1000 hectáreas. Casma no es una zona de gran extensión agrícola, tiene más o menos 6 o 7 mil hectáreas cultivables, esta hacienda era propiedad de Manuel Mujica Gallo.

El año 1930 este grupo de familias japonesas, arrienda la hacienda, se ponen de acuerdo, se organizan en una especie de tanamoshe ampliado (versión japonesa de la asociación cooperativa) y arriendan la hacienda, eso se termina cuando empieza la Segunda Guerra Mundial y Japón entra en guerra con Estados Unidos en 1941, entonces viene lo que ustedes ya conocen.

Cuando se produce la Segunda Guerra Mundial y Japón declara la guerra a Estados Unidos, América Latina, como ahora, era un feudo de Estados Unidos, entonces todos los gobiernos de América Latina, por su relación cercana con Estados Unidos, le declaran la guerra a Japón, y en los países como el Perú, donde la colonia japonesa era numerosa, comienza una hostilización y una persecución contra los japoneses, de tal manera que se aprovechan de la situación, y los negocios son saqueados, embargados, rematados y los japoneses, deportados. Son tratados como enemigos del Perú, les expropian todas sus propiedades, los bienes que tenían y son deportados.

Así se cierra el primer ciclo de los iniciales 45 años de la presencia japonesa en el Perú.

Ahí termina la gestión de los migrantes japoneses de esta hacienda. La mayor parte de los japoneses tiene que huir.

Crecí en un ambiente donde casi no había comunidad japonesa, quedarían unas 5 o 6 familias disgregadas en toda la provincia.

Esto se traduce en el severo debilitamiento del factor cultural, pérdida de comunidad cultural, porque en la medida que haya una comunidad más o menos extendida, ese grupo se reúne, hace fiestas, hay canto, comida, historias tradicionales, se comparten todas estas cosas, actividades económicas y sociales, pero en la medida que eso se debilita profundamente como en este caso, se pierde. Las pocas veces que se encontraban los japoneses de Casma era cuando mi padre iba al pueblo, a la ciudad, pues nosotros vivíamos en el campo, en la campiña, mi padre seguía teniendo terreno agrícola. 
En el pueblo quedaban 2 o 3 familias japonesas, a veces se reunía con ellos, iba a saludarlos, pero ya no quedaba gran cosa de cultura japonesa, hasta el idioma se debilita, pues no hay intercambio comunicativo permanente. Se produce la pérdida de costumbres, bailes, canto y de otras cosas, eso es lo que se produce con la disgregación, con esa diáspora de los japoneses durante la Segunda Guerra Mundial.

$\mathrm{Si}$ a alguno de ustedes le interesa conocer algo de ese período, un excelente texto que es muy ilustrativo es el libro que hace Luis Jochamowitz, sobre Fujimori, se llama Ciudadano Fujimori. Hay un buen análisis de lo que pasa en el Perú en momentos de la Segunda Guerra Mundial, y particularmente con la comunidad japonesa. Las consecuencias para la comunidad nipona han sido mucho más fuertes y peor de lo que yo imaginé, porque sabía algo de eso porque me reunía con algunos niseis mayores que yo que habían vivido esa experiencia, el hostigamiento, la hostilización, el saqueo y la expropiación de sus tiendas.

Luis Jochamowitz es uno de los que mejor ha retratado ese período.

\section{Construyendo una identidad intercultural}

Voy a terminar comentándoles algo que tiene que ver con un fenómeno más actual, que ahora se reconoce, se visibiliza y se trata especializadamente, las relaciones interculturales. Imagino que todos los que han tenido una familia medio disfuncional como la mía han experimentado esta situación. Mi padre era japonés, casi no sabía hablar castellano, hablaba mal, como esos japoneses antiguos que ahora ya no se encuentran, pero los chinos que ustedes ven, migrantes de primera generación van a escuchar las dificultades que tienen para hablar, en los japoneses era igual, hay palabras que las pronunciaba mal, letras que no las podía pronunciar y cosas por el estilo.

Mi padre no aprendió a leer ni a escribir en castellano, leía y escribía en japonés, pero en castellano no aprendió, y mi madre era campesina, de una comunidad de la sierra de Ancash, era bilingüe quechuahablante, semianalfabeta, entonces eso te plantea una serie de conflictos culturales.
Como les decía, el idioma japonés que no tenía una práctica frecuente se había debilitado en el caso de mi padre, a esa edad, ya no tenía ningún interés en enseñar su idioma, pero mi madre sí, mi madre era quechuahablante y quería que hablásemos quechua. Tengo una hermana que es un año mayor que yo, pero en esa época, les estoy hablando de 1958-1959, la exclusión y el estigma, de lo andino y del quechua, era terrible, era muy fuerte. Quien hablaba quechua era un serrano, un indio, alguien indeseable, entrabas en un conflicto con tu medio social. En el colegio, si tú querías hablar quechua, te apabullaban, te hacían bullying, como dicen ahora. Nosotros no queríamos aprender quechua, pero mi madre era una persona muy enérgica, de carácter fuerte, al final nos hizo aprender algo porque los diálogos domésticos los hacía en quechua, decía, trae agua, nos decía yaku apami, ya sabíamos que se refería agua y teníamos que ir, así ya aprendías algo, por eso aprendimos un poco.

Fue una experiencia complicada pero al final enriquecedora.

Cuando he empezado a reconstruir esa época y su contexto me he dado cuenta que japoneses y andinos tenían muchas cosas en común.

En mi casa había uno de esos radios a tubo, unos armatostes que eran como cajas de madera de mediano tamaño. Desaparecieron a mediados de los 60, cuando se inventa y difunde el radio a transistores.

En mi casa había ese radio a tubos. Era otro factor que lo convertía en espacio de vida pública de la zona. En la casa funcionaba un tambo, una tienda, y la gente de la periferia, de 10 cuadras a la redonda acudía y se reunía ahí, era el centro de la vida social de esa zona. Se intercambiaba información, se escuchaban los partidos de fútbol o noticias importantes, las novedades de la jornada, el estado de los trabajos y cultivos, etc.

Cuando se jugaban partidos de fútbol en Lima, aumentaba la concurrencia y el consumo de aguardiente y cigarrillos, el público era enteramente masculino. Ocasionalmente se jugaban partidas de naipes. Mi padre era muy aficionado al juego de naipes pero lo hacía en las festividades grandes que se celebraban en este valle, a fines de octubre, en honor a la Santísima Cruz que encarnaba al Señor de los Milagros, al que se rendía especial culto en la capital del Perú, por esa fecha. 


\section{La cercanía al mundo andino}

Sol en los Andes era un programa radial que Luis Pizarro Cerrón dirigía todos los días de 6.15 a 7 de la mañana, por radio El Sol, desde la capital del Perú. Era el único programa radial que escuchaba Yoichi. Era un programa de música vernácula. Huaynos en todas sus variantes y de las diversas regiones del Perú desfilaban anunciados por la potente y enterada voz de Pizarro Cerrón.

Años después me preguntaba por qué era este el único programa que escuchaba mi padre. Vine a descubrir la causa mucho después. Ambas, la música andina y la japonesa, son pentatónicas. A diferencia de la occidental se organizan por cinco notas y no siete, como la pentafónica-occidental. Había un sonido musical común.

Desaparecida la comunidad nipona del valle, la vida cotidiana absorbida por el trabajo del campo, generaba una relación permanente con los jornaleros venidos de la sierra ancashina, del Callejón de Huaylas y de Conchucos. Acudían masivamente en las épocas de siembre y cosecha resolviendo la necesidad de mano de obra, que en estos momentos se tornaba urgente.

Los jornaleros eran quechuahablantes, bilingües. Mi madre era la interlocutora principal, lo que hoy vendría a ser una facilitadora, la traductora, por su origen andino y ser quechuahablante como ellos.

Los que provenían del Callejón de Huaylas, estaban más asimilados al mundo criollo occidentalizado, su dominio del castellano era mayor, por lo general se expresaban en ese idioma. Los conchucanos eran más tradicionales, con fuerte persistencia de idioma y costumbres prehispánicas.

El compadrazgo era la institución más importante en las relaciones sociales. Denotaba cercanía y confianza entre los involucrados. Era sinónimo de respeto y especial afecto.

Con los trabajadores andinos tenía cosas en común. El trabajo duro y persistente y el valor del silencio. Eran de los que atesoraban la palabra y no fatigaban la lengua.

Parte de la asimilación a este mundo se expresaba en que Yoichi aprendió a chacchar coca (masticar la hoja de coca) y lo hacía al anochecer, antes de acostarse. Se ubicaba en una mesa grande que había en el salón principal, reclinaba la silla en la pared y cruzaba las piernas. Era su posición preferida para iniciar el chacchado. Pero nunca fue un verdadero chacchador, asumió esta afición como parte de su socialización con los andinos. No deglutía el jugo de la hoja mágica, lo escupía, con lo cual el efecto paradisiaco del alcaloide no se producía o alcanzaba niveles ínfimos. Lo que sí producía eran frecuentes quejas y regaños de mi madre, pues parte de los escupitajos no completaban su recorrido y terminaban manchando la pechera de la camisa.

La relación de Yoichi con los trabajadores y vecinos era cordial y amigable, dispuesto a la ayuda cuando era necesaria. Eran tiempos en que compartir parte de las cosechas traducía solidaridad. Los restos de la cosecha que no eran comercializables se dejaban en el campo para que los necesitados lo recogieran. Esta complementación de la cosecha se denominaba "rastrojeo". Institución que desapareció hace buen tiempo cuando todo se monetizó y las ansias de ganancia y acumulación sepultaron la solidaridad.

Lo más notable de esta relación era la horizontalidad, el sentido de igualdad social. Nunca percibí un trato diferenciado por consideraciones económicas, raciales o culturales. Es una de las cosas que luego he rescatado, valorado e incorporado en mi forma de vida. Es una de las enseñanzas más valiosas que recibí de este señor.

La gente, es buena o no es buena, como en la música. No hay más criterio de valoración.

\section{Hombre del Viejo Testamento}

El año 1953 fue una fecha aciaga para la agricultura del valle. Se produjo lo que ahora conocemos como Mega Niño, la alteración drástica de la temperatura de las aguas del Pacífico que trastornan las condiciones atmosféricas y van a producir efectos negativos en la producción agrícola.

Yoichi había sembrado una buena extensión de algodón. Los precios seguían siendo altos. La guerra de Corea condicionaba este precio.

Entonces, como ahora, los intermediarios de compañías exportadoras otorgaban adelantos para financiar la producción y asegurarse de contar con la cosecha. 
Fue un año catastrófico. De los 1000 o 1200 quintales que Yoichi proyectaba cosechar se cosecharon 60/70. Los productores del valle quedaron en la bancarrota. Nadie pudo cubrir lo recibido como adelanto, muchos ni siquiera lo intentaron.

Yoichi que había obtenido una cosecha tan magra como los demás, enyuntó sus seis bueyes, armó tres carretas y cargo los 60 quintales obtenidos y los llevó al depósito del comprador y se los entregó diciéndole, es todo lo que he cosechado y lo he traído para pagarte, y puedes quedarte también con los bueyes y carretas si es necesario. El comprador le respondió, Yoichi eres el único que ha venido a pagarme, y valoro tu esfuerzo cumplidor. Llévate lo que has traído, ya no me debes nada.

Era lo que se llama una persona de palabra. Pertenecía a la estirpe del Viejo Testamento. Los valores y códigos de honor estaban grabados a fuego en su memoria y corazón.

Estaban presentes a la hora de exigir el cumplimiento de los compromisos y también a la hora de honrarlos.

\section{Amigo de metáforas}

Su cama era la más abrigadora y amable que había en casa. Un par de pellejos de oveja de abundante y abrigadora lana recibía al buscador de sueño. Por muchos años tuvo como calefacción adicional natural, un perro mochica, calato, que entonces se le conocía como perro chino. El can pasaba su vida en la cama como fiel calefactor y ahuyentador de enfermedades reumáticas. Era una extravagancia que no recuerdo cuando finalizó. Duró probablemente unos 13-14 años, que es lo que viven estos animales. Luego sería reemplazado por una vulgar bolsa de agua caliente.

En invierno, esta cama era una querencia codiciada. Buscaba yo, ser el primero en introducirme para disfrutar de sus bondades térmicas y disputar al Viejo Yoichi y mi hermana esta bondad, algunas veces para cesar la rińa hacíamos sueño colectivo.

Acostumbraba meterme a la cama con medias, para aumentar el abrigo. Cierta vez Yoichi me dio un terrible mensaje. Tu ángel viene todas las noches a visitarte y saber cómo estás, te toca todo el cuerpo y cuando tus pies se hallan cubiertos por las medias, cree que no tienes tus pies, me dijo. Se aflige grandemente y se llena de pesar. Por eso no hay que dormir con las medias puestas.

Nunca más he vuelto a dormir con las medias puestas, hasta hace poco que empiezo a sentir frío por la edad invernal, y no tengo la calefacción de un perro mochica.

Pocas veces en mi vida he recibido un mensaje tan poderoso, metafórico o no.

\section{Sin jubilación ni AFP, felizmente}

Esos eran tiempos menos infamantes para la gente mayor. Ahora escucho o leo espantado: Tengo más miedo a jubilarme que a morir dicen algunos ancianos. Los 300 o 400 soles que la gente recibe de pensión de jubilación es ley que condena a los viejos a la pobreza y la indignidad.

Las masivas revueltas en Chile, en este año, han sido contra esto, un reclamo de la dignidad.

Yoichi murió a pocos días de cumplir 87 años. Ese día tuvo una jornada muy intensa.

Octubre es el mes en que el estío agoniza, las lluvias y la crecida de los ríos son inminentes. Por eso mismo, los días son más secos y calurosos que nunca.

El agua de riego agrícola entra en turno, se riega la sementera con una dotación de agua medida en tiempo y volumen. Lo indispensable para que las plantas sobrevivan. No son infrecuentes las disputas por el recurso en esta época.

Todos quieren un poco más de agua que el que le corresponde, a veces recurriendo a la sustracción y el robo. Yoichi pasó todo el día montado en su caballo para ir a la toma de agua (centro de distribución) y recuperar la dotación de agua que le correspondía y que otros regantes se llevaban arbitrariamente.

El intenso trajín y la cólera por estos estropicios, le pasaron factura. A las 6 de la tarde, hora del descanso cotidiano, pasó a la eternidad.

Hasta el último día disfrutó de su jornada de trabajo. El mundo rural sigue siendo portador de satisfacciones atávicas. Los que habitan ese mundo, siguen manteniendo su vinculación con la tierra, el agua, las plantas y los animales. 
La conexión cósmica persiste, por eso nunca son totalmente desdichados. No sufren de soledad cósmi$\mathrm{ca}$, que es la peor de todas las soledades.

Estas gentes, felizmente, no sufren jubilación ni padecen de la maldición de las AFP. Trabajan hasta el último día de su vida, y la viven gozosas y a pecho descubierto. Tienen el soporte material y afectivo de la red familiar y amical. Así vivió Yoichi sus días finales.

\section{El peso de la herencia. Carácter y ética}

La aparición del Fujimori político y presidente del Perú, ha sido una experiencia trascendental, marca un antes y después de la presencia de la comunidad nisei en nuestro país. Podríamos hablar del fin de un Segundo Ciclo de presencia nipona en el Perú.

Producido el episodio traumático de la Segunda Guerra Mundial, la comunidad japonesa mantuvo una vida muy discreta. Poca o nula exposición pública. Algunos personajes alcanzaron cierta notoriedad por su desempeño deportivo: Teófilo Toda, en el ciclismo, Humberto Suguimitzu, en el billar, Olga Asato, en vóley, Juan Nakajata y los hermanos Iwasaki, en el fútbol, Olga Shimazaki en ballet. Es en el arte y la poesía donde tuvieron representantes más destacados. Tilsa Tsuchiya, Venancio Shinke, Eduardo Tokeshi en artes plásticas, en poesía, José Watanabe, Nicolás Matayoshi, y Augusto Higa en literatura. Es en estos campos donde han destacado con mayor presencia. Igualmente en la actividad empresarial, Kiotake Tamashiro, Fernando Ikeda en comercialización y crianza de pollos, Samuel Matsuda en crianza de porcinos y pollos, Hiraoka en comercio de electrodomésticos, Maruy en bazar. En la gastronomía, renglón tan valorado en las últimas décadas, Humberto Sato, Rosita Shimura, entre otros.

En la generación actual de artistas plásticos destacan Runcie Tanaka, Oswaldo Higuchi, Arturo Kubota, Jorge Miyagi, Kareen Nishimura, Jorge Oka, Maya Watanabe, Eliana Otta, entre otros. En poesía, Doris Moromisato, Tilsa Otta. En el deporte automovilístico, Fernanda Kanno.

Disciplina, esfuerzo, responsabilidad, virtudes ancestrales puestas en práctica permitieron estos logros y consolidaron la imagen de la comunidad japonesa como una colectividad que realiza una gran contribución a un Perú mejor.
El desempeño del expresidente Fujimori resquebrajó esta imagen y lo tradujo a la mediocridad, una comunidad más entre las varias que radican en nuestro país.

No abundaremos en criticar su estilo de gobierno ni su vocación autoritaria. Podemos aceptar la opinión indulgente, que hace un balance positivo de su primera época (derrota del terrorismo y control de la crisis económica) criticando su ansia de continuismo en el poder y, especialmente, la malversación de fondos públicos.

Un acucioso trabajo de investigación del periodista Ángel Páez, publicado en el diario La República, del año 2004, señala a Alberto Fujimori comprometido en negocios turbios en Japón donde radicó algunos ańos, y de amasar una fortuna a costa del erario público.

El que haya pretendido convertir a su familia en una dinastía para perennizar su vigencia política, ha hecho de su paso por la vida pública una experiencia trágica y patética.

Lo que interesa resaltar en esta nota es su falta de carácter, de entereza, a la hora de afrontar situaciones difíciles.

Siete meses después de producido el golpe de estado del 5 de abril de 1992, un grupo de altos oficiales del ejército, encabezado por el general Jaime Salinas Sedó, produce una rebelión para desalojar a Fujimori del poder y, según los rebeldes, restaurar la legalidad constitucional, reivindicando la Constitución del año 1979.

Informado de la rebelión, el presidente Fujimori acude raudamente a la embajada del Japón y solicita asilo. Abandona palacio de gobierno y abdica de su responsabilidad ante el país.

Esta conducta es impropia de un líder que dirige una nación y tiene miles de seguidores. Es un capitán de barco que lo abandona apenas se producen unas marejadas, dejando a pasajeros y tripulantes a la deriva. De japonés, esta conducta no tiene nada, es un acto de cobardía flagrante.

El otro suceso que evidencia su estilo de criollo victoriano, antes que japonés, lo muestra cuando renuncia por Fax a la presidencia de la República y se queda asilado en Japón.

En ambas situaciones este personaje carece completamente del sentido del honor y compromiso de un japonés promedio. En lugar de asumir las conse- 
cuencias por haber violado el orden constitucional, huye de una forma estrepitosa. Es un limeño criollo, lo que en lenguaje coloquial diríamos, un Pepe el vivo, un pendejo.

No es algo sencillo el compromiso ético. La llegada de la Buena Nueva y su portador, incluyen la profunda renovación del concepto de justicia y legalidad. Una gigantesca maraña de leyes y mecanismos que terminan confundiendo y desvirtuando el sentido de justicia. Muchas leyes y poca justicia. El Nuevo Testamento no es la panacea.

La inmensa mayoría de integrantes de la comunidad nisei en el Perú sigue cultivando las virtudes y valores que recibieron de los primeros emigrantes japoneses. Estos valores siguen siendo un bien preciado y cultivado con esmero y perseverancia por los descendientes de los que vinieron desde el país del sol naciente, que llegaron en el Sakura Maru, primer barco nipón que navegó aguas peruanas portando una valiosa carga que ha enriquecido y engrandecido la hermosa tierra de Pachacamac.

Sakura Maru, significa en idioma japonés, La puerta de la flor del cerezo, que es la flor más preciada en el Japón. En eso se convirtió el Perú para los emigrantes y sus descendientes, en la flor más preciada.

La comunidad nikkei se convierte así en torrente que se integra al caudal de todas las sangres, que es el Perú de nuestros días.

\section{Bibliografía}

Arguedas, José María (1968). No soy un aculturado. Discurso del escritor José María Arguedas en el acto de entrega del premio «Inca Garcilaso de la Vega». Lima, Perú.

Higa, Augusto (2019). Japón no da dos oportunidades. Editorial Animal del Invierno, Lima.

Fukumoto Sato, Mary (1974). Migrantes japoneses y sus descendientes en el Perú. Tesis de Bachiller. UNMSM. Lima.

Hernández, Max (1993). Memoria del bien perdido. Conflicto, identidad y nostalgia en el Inca Garcilaso de la Vega. IEP/Biblioteca Peruana de Psicoanálisis, Lima.

Matos Mar, José (1984). Crisis del Estado y desborde popular. El nuevo rostro del Perú en la década de 1980. IEP, Lima, Perú.

Morimoto, Amelia (1979). Los inmigrantes japoneses en el Perú. Taller de Estudios Andinos. Universidad Agraria del Perú, Lima.

Rodríguez Pastor, Humberto (2018). El peón y empresario Nikumatsu Okada y la comunidad japonesa del valle de Chancay (1900-1950). Editorial Asociación Peruano Japonesa, Lima, Perú.

TANizaki, Junichiro (1994). El elogio de la sombra. Ediciones Siruela, Madrid.

TanizaKI, Junichiro (2013). Las hermanas Makioka. Ediciones Siruela. Madrid. 